\title{
Adipose-derived mesenchymal stem cells inhibit cell proliferation and migration and suppress extracellular matrix synthesis in hypertrophic-scar and keloid fibroblasts
}

\author{
FANG XIE, LI TENG, JIAJIE XU, JIANJIAN LU, CHAO ZHANG, \\ LIYA YANG, XIAOYANG MA and MINGHAO ZHAO \\ Cranio-Maxillo-Facial Surgery Department 2, Plastic Surgery Hospital, \\ Chinese Academy of Medical Sciences and Peking Union Medical College, Beijing 100144, P.R. China
}

Received September 10, 2019; Accepted March 26, 2020

DOI: $10.3892 /$ etm.2020.9571

\begin{abstract}
Pathological scars occur during skin wound healing, and the use of adipose-derived stem cells (ADSCs) is one of the various treatments. The present study aimed to investigate the in vitro effects of ADSCs on the biological properties of hypertrophic scar fibroblasts (HSFs) and keloid fibroblasts (KFs), such as proliferation, migration, and the synthesis of extracellular matrix proteins. Transwell chambers were used to establish a co-culture system of ADSCs with normal skin fibroblasts (NFs), HSFs or KFs. The effect of ADSCs on the proliferation of fibroblasts was evaluated by CCK 8 measurement, while the migration ability of fibroblasts was assessed using cell scratch assay. The expression of extracellular matrix proteins was measured by immunoblotting. Co-culture of NFs with ADSCs did not affect cell proliferation and migration, nor the expression of extracellular matrix proteins [collagen-I, collagen-III, fibronectin (FN) and $\alpha$-smooth muscle actin ( $\alpha$-SMA)] in NFs. However, as with the inhibitor SB431542, ADSCs significantly inhibited cell proliferation and migration and the expression of extracellular matrix proteins (collagen-I, collagen-III, FN and $\alpha$-SMA), but also suppressed the protein expression of transforming growth factor $\beta 1$ (TGF- $\beta 1$ ), phosphorylated (p-) mothers against decapentaplegic homolog (Smad) 2, p-Smad3 and Smad7 in HSFs and KFs. The results show that ADSCs inhibited cell proliferation and migration and the expression of extracellular matrix proteins in HSCs and KFs in vitro, possibly through inhibition of the TGF- $\beta 1 /$ Smad pathway.
\end{abstract}

Correspondence to: Professor Li Teng, Cranio-Maxillo-Facial Surgery Department 2, Plastic Surgery Hospital, Chinese Academy of Medical Sciences and Peking Union Medical College, 33 Ba-Da-Chu Road, Shi Jing Shan, Beijing 100144, P.R. China

E-mail: tenglpshcams@163.com

Key words: adipose-derived mesenchymal stem cells, fibroblasts, migration, proliferation, extracellular matrix

\section{Introduction}

A pathological scar is a fibroproliferative disorder that is characterized by the excessive repair by tissue repair cells, mainly fibroblasts, through the excessive synthesis and secretion of extracellular matrix during skin wound healing (1). Not only do pathological scars seriously affect the physical appearance, but they are also usually accompanied with infection, itching, pain and ulceration $(2,3)$. In addition, they can cause serious dysfunction or disfigurement, which obviously affects the quality of life of the patient $(2,3)$. Despite the existence of different clinical treatments for pathological scars, such as surgical resection, laser treatment, cortisol injection therapy, and compression therapy, no treatment method is known to achieve a satisfactory therapeutic effect $(4,5)$.

Mesenchymal stem cells, derived from the mesoderm at the embryonic stage, are adult stem cells with self-renewal and multi-directional differentiation potential. During wound healing, mesenchymal stem cells have been shown to regulate macrophages and T-cell function $(6,7)$, neutralize oxidizing substances (8), secrete anti-fibrotic factors (9), strengthen the function of dermal fibroblasts (10), promote vascularization and stability of blood vessels, and induce the differentiation of dermal layer cells, which can help in healing of the tissue (11). In addition, previous studies have shown that mesenchymal stem cells, bone marrow mesenchymal stem cells $(12,13)$, umbilical cord mesenchymal stem cells (14) and chorionic mesenchymal stem cells (15) can promote wound healing and treat various types of fibrotic diseases.

Adipose-derived stem cells (ADSCs), which have been isolated from human adipose tissue suspensions, have multipotential differentiation capacity $(16,17)$. In addition to possessing the characteristics of general stem cells, ADSCs have the ability of self-renewal and multiplication, and can also differentiate into many specific functional cell lines $(16,17)$. Compared with other mesenchymal stem cells, ADSCs have a wide range of sources, only lead to minor damage in the donor site, have a good tissue compatibility, are easy to culture in vitro, have weak immunogenicity and relatively uncontroversial ethically $(16,17)$. It has been shown that ADSCs can help repair tissue and organ damage $(18,19)$, as well as promote 
wound healing through their paracrine effects in diabetic and nude mice $(20,21)$. However, the molecular mechanisms by which ADSCs promote wound healing remain to be elucidated.

The present study demonstrated that co-culture with ADSCs inhibited the proliferation, migration, and protein expression of extracellular matrix, and also inhibited the transforming growth factor $\beta 1$ (TGF- $\beta 1$ )/mothers against decapentaplegic homolog (Smad) pathway in hypertrophic scar fibroblasts and keloid fibroblasts.

\section{Materials and methods}

Tissue specimens and patients. Adipose tissue, used to extract adipose-derived mesenchymal stem cells, was derived from 5 healthy subjects ( 2 males and 3 females; $25-42$ years old) undergoing local liposuction from October 2018 to May 2019 at Plastic Surgery Hospital, Chinese Academy of Medical Sciences and Peking Union Medical College (Beijing, China). Hypertrophic scar tissues were obtained from 9 patients with hypertrophic scars, keloid tissues were obtained from 14 keloid patients, and 5 normal skin tissues were obtained from post-reconstruction cat ear malformation and cosmetic outpatient surgeries. Patients with the following criteria were excluded from the study: i) Less than 6 months with the condition; ii) infection in the lesion; iii) radiation therapy or steroid injection; iv) pathological scar disease combined with other hereditary diseases, body fluid transmission diseases (such as HIV and HBV), malignant tumors and skin diseases; and, v) age $>55$ years or $<16$ years.

All the participants in the present study signed informed consents, and the study was approved by the Ethics Committee of Plastic Surgery Hospital, Chinese Academy of Medical Sciences and Peking Union Medical College.

Isolation, culture and identification of ADSCs. The isolation, culture and identification (Fig. S1) of ADSCs was performed according to the protocol of Gao et al (22). Briefly, the adipose tissue was obtained under aseptic conditions and cut into 1-2 $\mathrm{mm}$ slices, then incubated with an equal volume of $0.1 \%$ type I collagen (cat. no. 17018029; Thermo Fisher Scientific, Inc.) at $37^{\circ} \mathrm{C}$ for $45 \mathrm{~min}$. The precipitate was centrifuged $(1,200 \mathrm{x} \mathrm{g}$ at room temperature) for $15 \mathrm{~min}$ and the cell pellet was resuspended in a low-glucose DMEM medium (cat. no. 21885108; Gibco; Thermo Fisher Scientific, Inc.) supplemented with 1\% penicillin-streptomycin (cat. no. 15140163; Thermo Fisher Scientific, Inc.), $10 \%$ fetal bovine serum (cat. no. 10437028; Thermo Fisher Scientific, Inc.), and $640 \mu \mathrm{g} / \mathrm{ml}$ glutamine (cat. no. G3126; Sigma-Aldrich; Merck KGaA). The cells were incubated at $37^{\circ} \mathrm{C}$ with $5 \% \mathrm{CO}_{2}$, and the medium was changed after 4 days of culture. Following that, the medium was changed every two days. Cells from passages 3-6 were used in the experiments.

Isolation, culture and identification of fibroblasts. Fibroblasts, including normal skin fibroblasts, hypertrophic scar fibroblasts and keloid fibroblasts, were isolated, cultured and identified as previously described $(23,24)$. Briefly, normal skin tissue, hypertrophic scar tissue or keloid tissue was incubated in a PBS buffer solution containing $1 \%$ streptomycin for $15 \mathrm{~min}$, then cut into $0.5 \times 0.5 \mathrm{~cm}$ sections, which were incubated in a cell culture dish containing low-glucose DMEM medium (cat. no. 21885108; Gibco; Thermo Fisher Scientific, Inc.) supplemented with $1 \%$ penicillin-streptomycin (cat. no. 15140163; Thermo Fisher Scientific, Inc.), 10\% fetal bovine serum (cat. no. 10437028; Thermo Fisher Scientific, Inc.), and $640 \mu \mathrm{g} / \mathrm{ml}$ glutamine (cat. no. G3126; Sigma-Aldrich; Merck KGaA). The incubation was continued until a dense monolayer ( $80 \%$ confluency) of cells formed around the tissue pieces. Cells from passages 3-6 were used in the experiments.

Transwell chamber co-culture system. A Transwell chamber (cat. no. 140652; Thermo Fisher Scientific, Inc.) was used to culture ADSCs with fibroblasts. The co-culture system was performed as follows: $1.5 \times 10^{3}$ ADSCs were added per well in the upper chamber of a 12-well plate Transwell chamber, with $0.5 \mathrm{ml}$ of culture medium, and $3 \times 10^{3}$ ADSCs per well were inoculated into the lower chamber with $1.5 \mathrm{ml}$ culture medium. For the single culture system only $3 \times 10^{3}$ ADSCs were inoculated per well into the lower chamber, with or without adding SB431542 (cat. no. s4317; Sigma-Aldrich; Merck KGaA) into the culture medium.

Cell proliferation assay. The viability of fibroblasts was evaluated using the MTT Cell Proliferation and Cytotoxicity Assay kit and the BrdU Cell Proliferation Assay kit (cat. no. C0075S; Beyotime Institute of Biotechnology). Briefly, after $4 \mathrm{~h}$ of incubation with MTT $(10 \mu 1,10 \mathrm{mg} / \mathrm{ml})$, the supernatant was removed and $100 \mu \mathrm{l}$ DMSO was added. After $30 \mathrm{~min}$, the optical density (OD) was measured using a plate reader (ELx808; BioTek Instruments, Inc.).

Cell scratch test. A scratch was created perpendicular to the back of the horizontal line using a vertically positioned (non-tilted) $200 \mu \mathrm{l}$ pipette tip. The scratched cells were removed by washing the cells 3 times with PBS. The cells were then cultured at $37^{\circ} \mathrm{C}$ and $5 \% \mathrm{CO}_{2}$ in a serum-free DMEM medium, and images captured after 4 days using a light microscope (magnification, x200; CKX41; Olympus Corporation).

Western blot analysis. Collagen-I, collagen-III, fibronectin (FN), $\alpha$-smooth muscle actin ( $\alpha$-SMA), TGF- $\beta 1$, Smad2, Smad3, phosphorylated (p-) Smad2, p-Smad3 and Smad7 proteins were detected by western blotting as previously described (25). Total protein was extracted from cells using a cell total protein extraction kit (cat. no. P1250), and the protein concentration was measured using a BCA kit (cat. no. P1511; both from Applygen Technologies, Inc.). Subsequently, $40 \mu \mathrm{g}$ total protein/sample were analyzed via 8-10\% SDS-PAGE, and the proteins were transferred onto a PVDF membrane (cat. no. 3010040001; Merck \& Co., Inc.). The antibodies (Abcam) were diluted according to the manufacturer's guidelines. The membranes were blocked for $1 \mathrm{~h}$ at room temperature using a blocking solution containing 5\% skimmed milk in TBS-0.05\% Tween-20. The membranes were then incubated with the primary antibodies: Collagen-I (1:1,000; cat. no. ab34710), collagen-III (1:1,000; cat. no. ab184993), FN (1:2,000; cat. no. ab2413), $\alpha$-SMA (1:1,500; cat. no. ab5694), TGF- $\beta 1$ (1:1,000; cat. no. ab215715), Smad2 (1:200; cat. no. ab40855), Smad3 (1:1,000; cat. no. ab40854), p-Smad2 (1:500; cat. no. ab188334), p-Smad3 (1:1,000; cat. no. ab52903) 
A
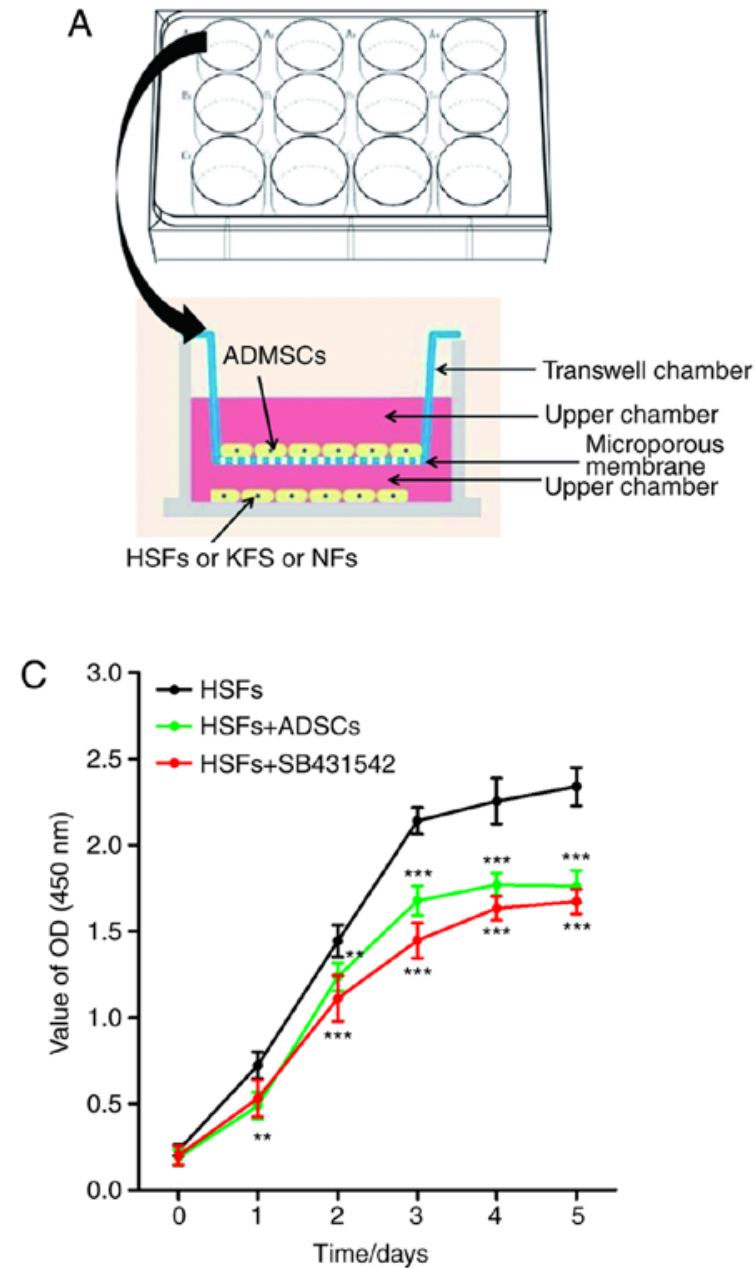

B
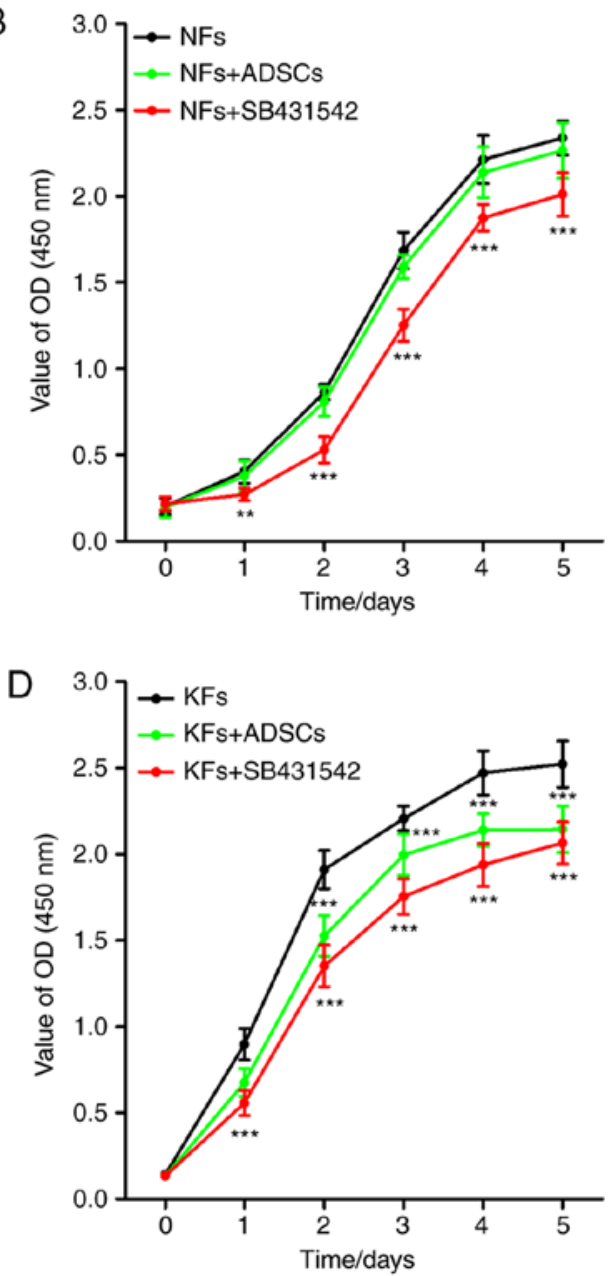

Figure 1. Effects of ADSCs on the proliferation of NFs, HSFs and KFs. (A) Co-culture system of ADSCs with NFs, HSFs and KFs. (B) The proliferation of NFs in different culture environments. ${ }^{* *} \mathrm{P}<0.001$ vs. NFs group; ${ }^{* * *} \mathrm{P}<0.001$ vs. NFs group. (C) The proliferation of NFs in different culture environments. ${ }^{* *} \mathrm{P}<0.01$ vs. HSFs group; ${ }^{* * *} \mathrm{P}<0.001$ vs. HSFs group. (D) The proliferation of NFs in different culture environments. ${ }^{* * *} \mathrm{P}<0.001$ vs. KFs group. ADSCs, adipose-derived mesenchymal stem cells; NFs, normal skin fibroblasts; HSFs, hypertrophic scar fibroblasts; KFs, keloid fibroblasts.

and Smad7 (1:1,000; cat. no. ab216428), diluted in the blocking solution, for $2 \mathrm{~h}$ at room temperature, then incubated with the secondary antibodies: Goat anti-rabbit IgG H\&L HRP-conjugated (1:2,000; cat. no. ab6721) and goat Anti-Mouse IgG H\&L HRP-conjugated (1:3,000; cat. no. ab6789), diluted in blocking solution, for $1 \mathrm{~h}$ at room temperature. Finally, the signal was visualized with ECL solution (cat. no. K22020; Abbkine Scientific Co., Ltd.). ImageJ software (v3.0; National Institutes of Health) was used to analyze the protein bands, and $\beta$-actin was for normalization.

Statistical analysis. SPSS 20.0 (SPSS, Inc.) was used for statistical analysis of the data. Student's t-test was used to compare between two groups, while multi-group comparisons were performed using one-way ANOVA followed with Duncan's post hoc test. $\mathrm{P}<0.05$ was considered to indicate a statistically significant difference.

\section{Results}

ADSCs inhibit the proliferation of HSFs and KFs. Transwell chambers were used to establish a co-culture system of ADSCs and NFs, HSFs or KFs (Fig. 1A). No significant difference in the proliferation of NFs was observed between NFs single culture system and ADSCs + NFs co-culture system. However, SB431542 inhibited the proliferation of NFs in the NFs single culture system (Fig. 1B). As shown in Fig. 1C and D, the proliferation of HSFs and KFs was higher in the single culture system, compared with that in the co-culture system with ADSCs. As with the NFs, SB431542 significantly inhibited the proliferation of HSFs and KFs in the single culture system.

ADSCs inhibit the migration of HSFs and KFs. While co-culture with ADSCs did not affect the migration of NFs, SB431542 significantly inhibited the cell migration of NFs in NFs single culture system (Fig. 2A). In addition, the migration distance of HSFs and KFs were significantly higher in the single culture system, compared with their migration distance following co-culture with ADSCs (Fig. 2B and C). SB431542 significantly inhibited the migration of HSFs and KFs in the single culture system.

ADSCs reduce the expression of extracellular matrix proteins in HSFs and KFs. The expression of extracellular matrix proteins, such as collagen-I, collagen-III and FN, and the extracellular matrix-related proteins, such as $\alpha$-SMA, in NFs, HSFs 
A

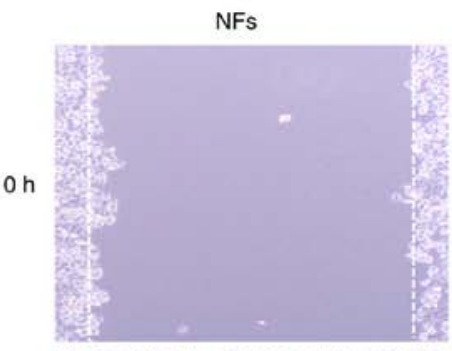

$96 \mathrm{~h}$

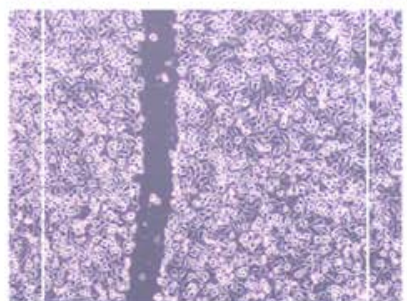

B

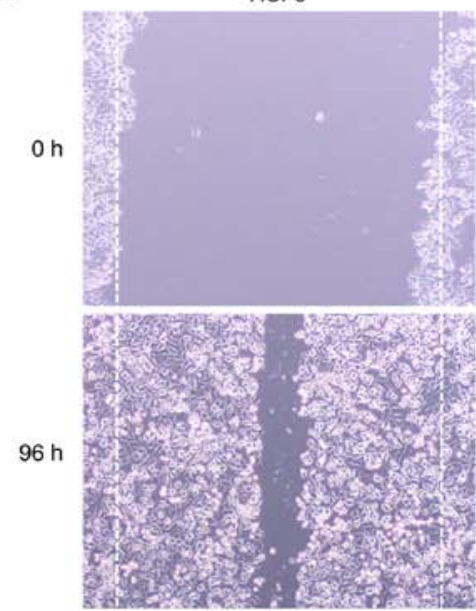

C

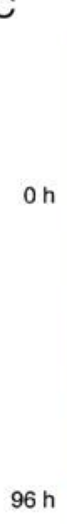

$96 \mathrm{~h}$

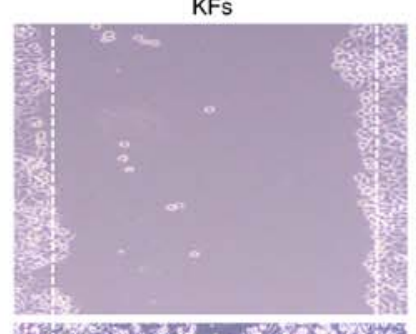

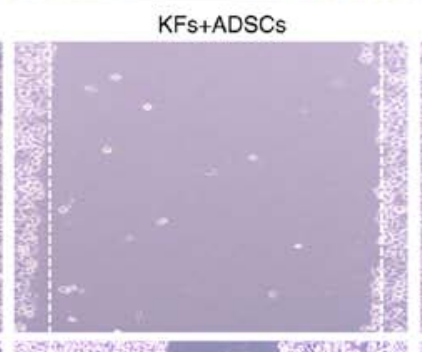

HSFs+ADSCs
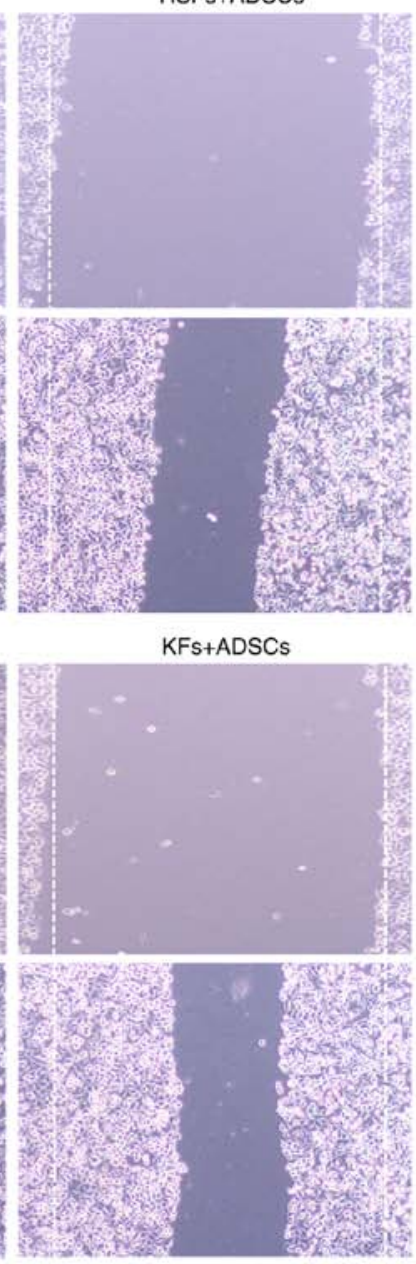

NFs+ADSCs
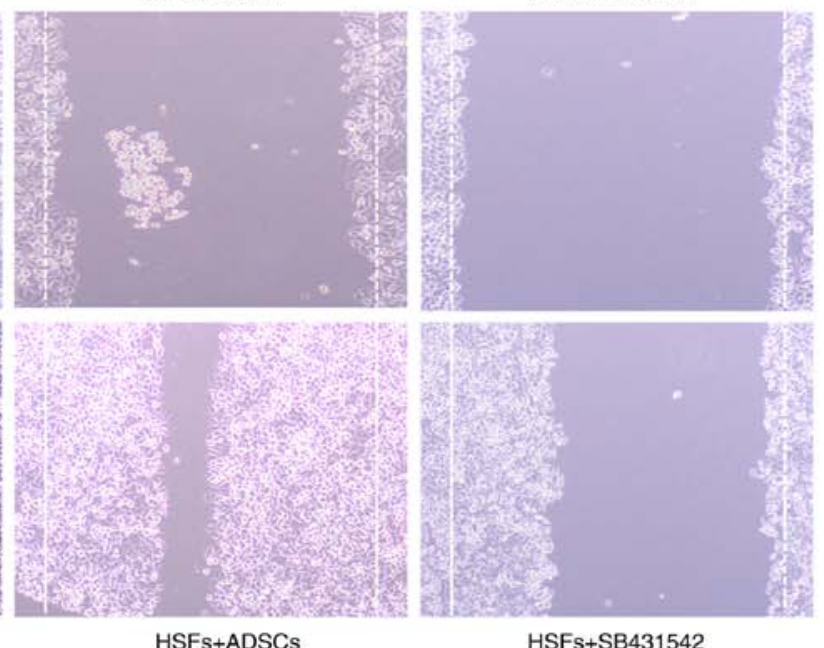

HSFs+SB431542

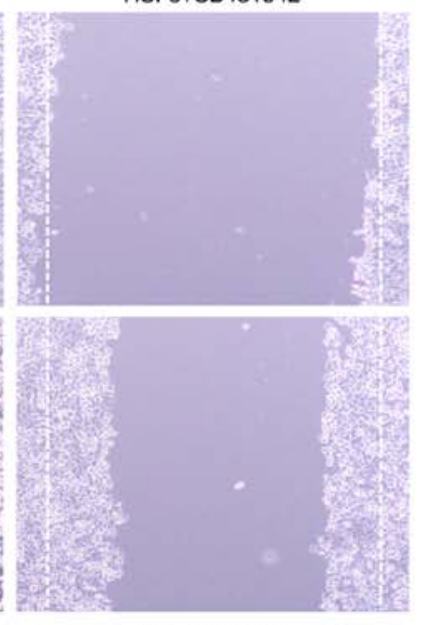

KFs+SB431542

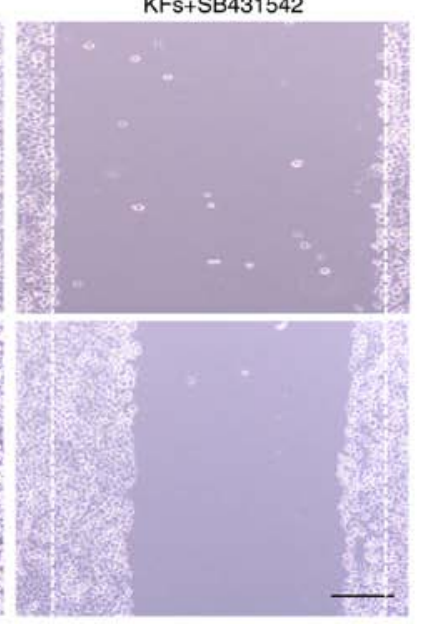

Figure 2. Effects of ADSCs on the proliferation of NFs, HSFs and KFs. (A) Cell scratch assays were used to measure the migration of NFs in different culture environments. (B) Cell scratch assays were used to measure the migration of HSFs in different culture environments. (C) Cell scratch assays were used to measure the migration of KFs in different culture environments. Scale bar $=100 \mu \mathrm{m}$. ADSCs, adipose-derived mesenchymal stem cells; NFs, normal skin fibroblasts; HSFs, hypertrophic scar fibroblasts; KFs, keloid fibroblasts.

and KFs, were measured in the single culture systems and in the co-cultured cells (Fig. 1A). There was no significant difference in the expression of collagen-I, collagen-III, FN and $\alpha$-SMA protein in NFs cultured alone and in those co-cultured with ADSCs. However, the expression of collagen-I, collagen-III, $\mathrm{FN}$ and $\alpha$-SMA proteins was significantly decreased in NFs treated with SB431542. Of importance, the expression of
collagen-I, collagen-III, FN and $\alpha$-SMA proteins in HSFs and KFs from the single culture system were significantly lower than those from the co-culture system with ADSCs (Fig. 3A-C). On the other hand, SB431542 reduced the protein expression of collagen-I, collagen-III, FN and $\alpha$-SMA in HSFs and KFs from the single culture system (Fig. 3A-C). In addition, the concentration of hydroxyproline (HYP) in HSFs and 

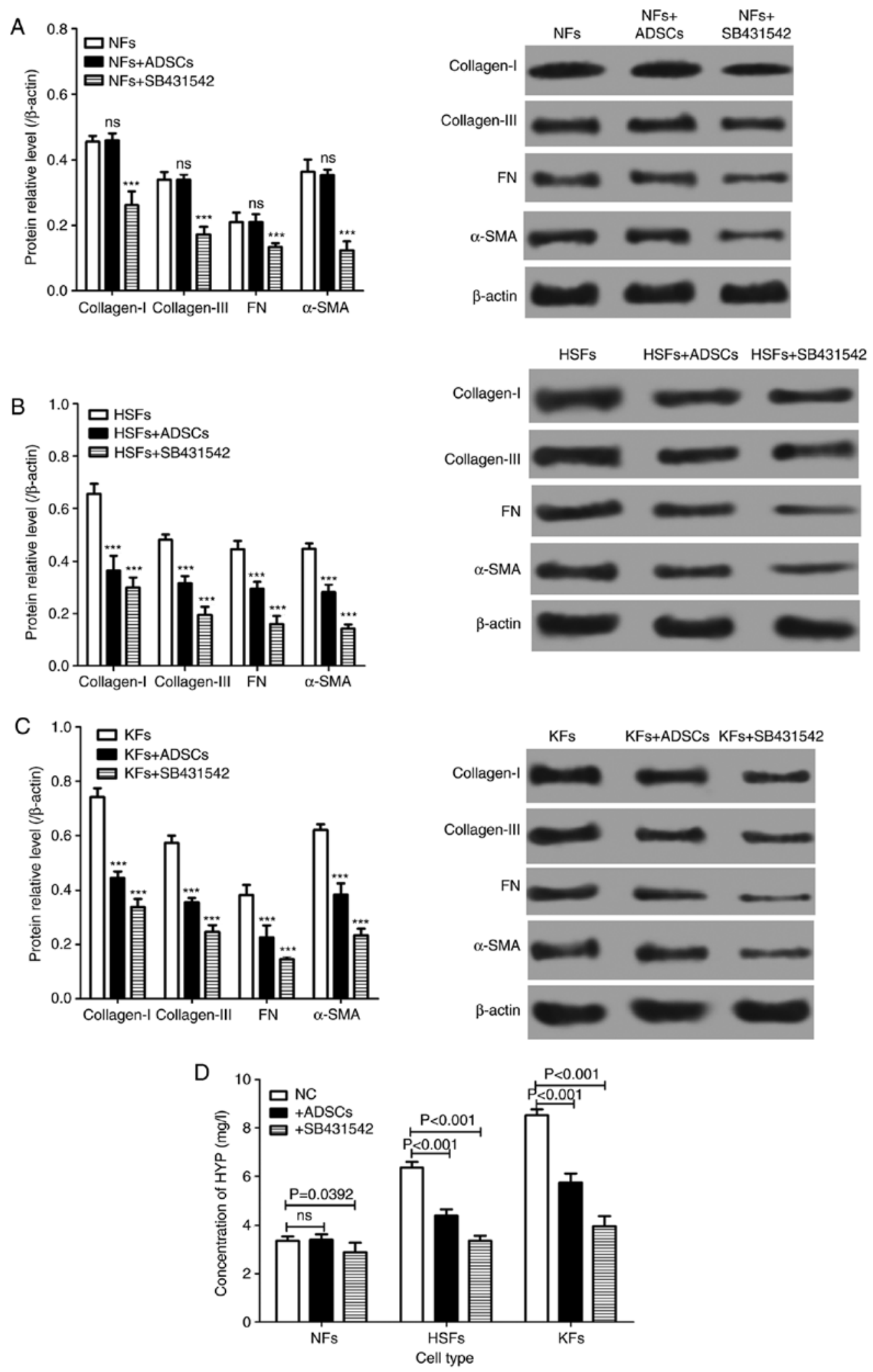

Figure 3. Effects of ADSCs on the synthesis of extracellular matrix in NFs, HSFs and KFs. Western blotting was used to detect the expression of collagen-I, collagen-III, FN and $\alpha$-SMA protein in (A) NFs ( ${ }^{* * * *} \mathrm{P}<0.01$ vs. NFs group), (B) HSFs $\left({ }^{* * * *} \mathrm{P}<0.01\right.$ vs. HSFs group) and (C) KFs ${ }^{(* * *} \mathrm{P}<0.01$ vs. KFs group). (D) The concentration of HYP in the culture medium of NFs, HSFs and KFs with different culture environments. HYP; hydroxyproline; ADSCs, adipose-derived mesenchymal stem cells; NFs, normal skin fibroblasts; HSFs, hypertrophic scar fibroblasts; KFs, keloid fibroblasts; ns, not significant..

KFs from the single culture system was significantly lower compared with that from the co-culture system with ADSCs, and SB431542 reduced the concentration of HYP from the single culture system (Fig. 3D).
ADSCs inhibit TGF- $\beta 1 /$ Smad pathway in HSFs and KFs. The TGF- $\beta 1 /$ Smad pathway is a signaling pathway that is closely associated with cell proliferation and migration, and to extracellular matrix synthesis in fibroblasts. As shown in 

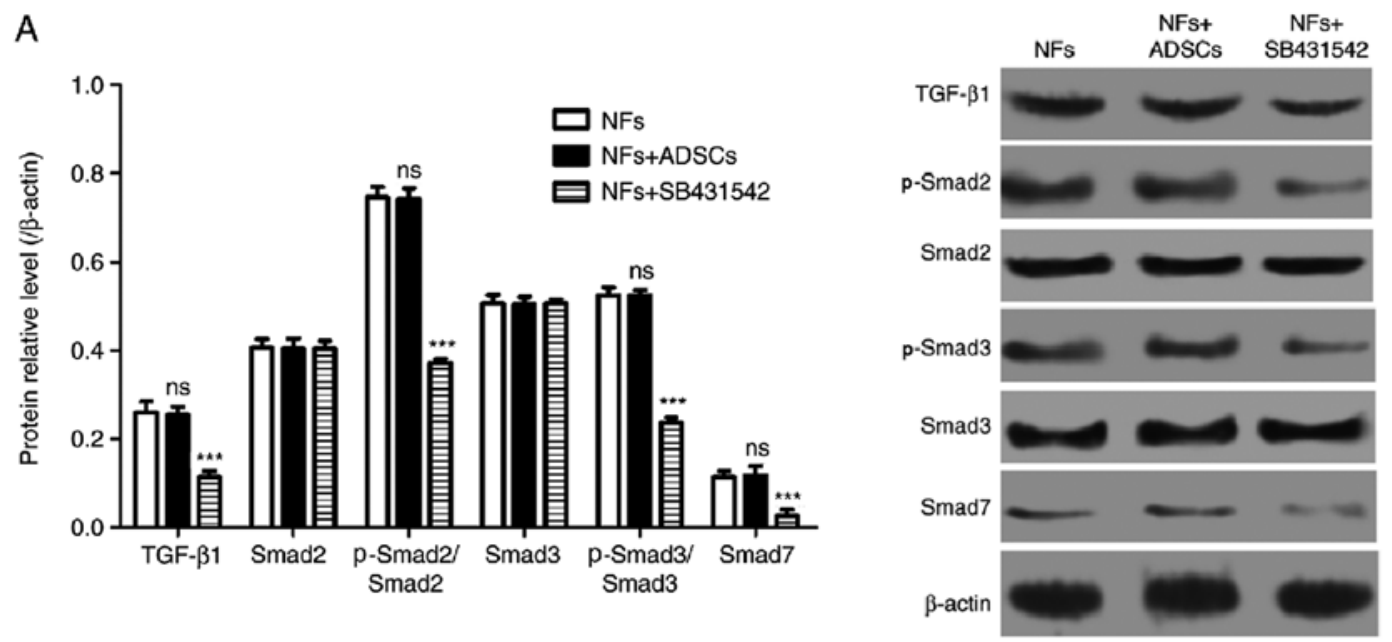

B
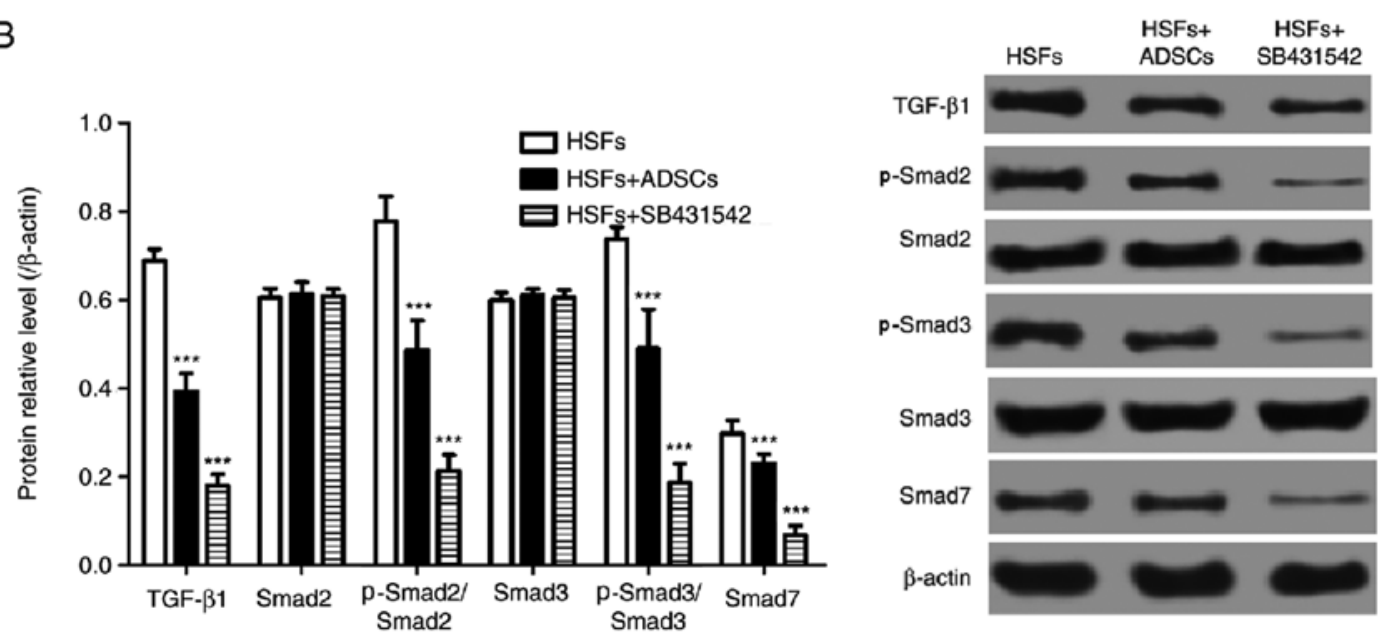

C
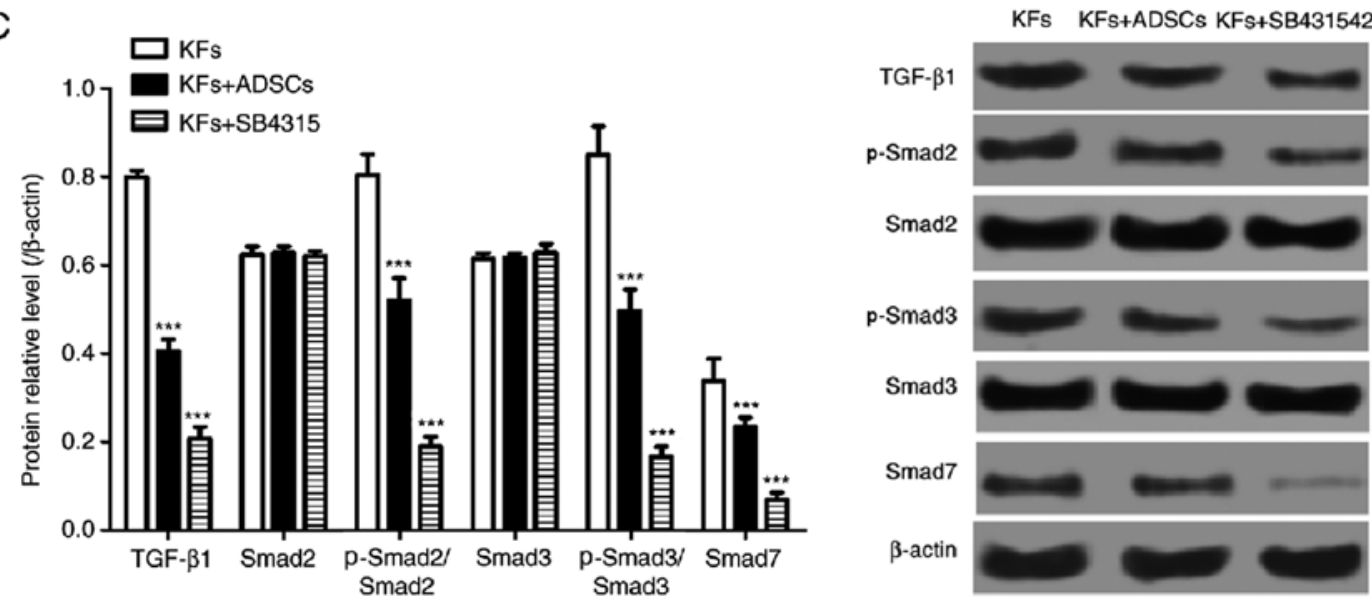

Figure 4. Effects of ADSCs on TGF- $\beta 1 /$ Smad pathway in NFs, HSFs and KFs. A-C, Western blot was used to detect the expression of TGF- $\beta 1$, Smad2, Smad3, p-Smad 2, p-Smad 3 and Smad 7 protein in (A) NFs ${ }^{(* * *} \mathrm{P}<0.01$ vs. NFs group), (B) HSFs ( ${ }^{* * * *} \mathrm{P}<0.01$ vs. HSFs group) and (C) KFs $\left(^{* * *} \mathrm{P}<0.01\right.$ vs. KFs group). ADSCs, adipose-derived mesenchymal stem cells; TGF- $\beta 1$, transforming growth factor $\beta 1$; Smad, mothers against decapentaplegic homolog; NFs, normal skin fibroblasts; HSFs, hypertrophic scar fibroblasts; KFs, keloid fibroblasts; p-, phosphorylated.; ns, not significant.

Fig. 4, the protein expression of TGF- $\beta 1, \mathrm{p}-\mathrm{Smad} 2 / \mathrm{Smad} 2$, p-Smad3/Smad3 and Smad7 in NFs from the single culture system were similar to that from the co-culture systems. However, the selective inhibitor of the TGF- $\beta 1 / \mathrm{Smad}$ signaling pathway, SB431542, significantly decreased the protein expression of TGF- $\beta 1, \mathrm{p}-\mathrm{Smad} 2 / \mathrm{Smad} 2$, p-Smad3/Smad3 and Smad7 in NFs. In addition, the protein expression of TGF- $\beta 1, \mathrm{p}-\mathrm{Smad} 2 / \mathrm{Smad} 2, \mathrm{p}-\mathrm{Smad} 3 / \mathrm{Smad} 3$ and Smad7 in HSFs and KFs from the single culture systems were significantly higher than those from the co-culture systems with ADSCs (Fig. 4B and C). Furthermore, SB431542 also suppressed TGF- $\beta 1$, p-Smad2, p-Smad3 and Smad7 expression in HSFs and KFs in the single culture systems (Fig. 4B and C). 


\section{Discussion}

The complex causes and mechanisms have led to a number of hypotheses to explain pathological scars formation, such as the immunoinflammatory over-the-sun holiday hypothesis (i.e. excessive inflammation results in extracellular matrix deposition and tissue fibrosis), the cytokine regulatory disorder hypothesis, the cell matrix line disorder hypothesis and the epigenetic hypothesis $(26,27)$. However, no single hypothesis can fully explain the mechanism of pathological scars formation. Despite that, various hypotheses can hold several views on the causes of pathological scar formation; excessive fibroblast proliferation and deposition of extracellular matrix are considered the most significant pathological changes during the development of pathological scars $(26,27)$. Therefore, inhibition of fibroblasts proliferation and the suppression of extracellular matrix synthesis by fibroblasts could be potential targets for the prevention and treatment of pathological scars (28).

Previous studies have shown that the transplantation of mesenchymal stem cells into the large area of wounds can accelerate wound healing, improve healing quality and reduce scar formation $(29,30)$. This suggests that mesenchymal stem cells can inhibit scar formation, which provides an approach for the treatment of wounds and pathological scars $(29,30)$. Previous studies have shown that mesenchymal stem cells can inhibit scar hyperplasia through myofibroblasts regulation $(31,32)$, immune response regulation (33), ROS/RNS homeostasis (34) and angiogenesis induction (35). The present study demonstrated that ADSCs inhibited cell proliferation and migration, as well as the protein expression of collagen-I, collagen-III, FN and $\alpha$-SMA in hypertrophic scar fibroblasts and keloid fibroblasts. Evidently, the present study only investigated the effect of ADSCs on proliferation, migration and the synthesis of extracellular matrix in HSFs and KFs in vitro. The current study was limited to outside the body to circumvent the complex environment inside the body, and its conclusion needs to be confirmed in vivo. With the advancements in cell therapy and stem cells understanding, ADSCs are regarded as model seed cells for cell therapy due to their ability to secrete a large number of active factors $(36,37)$ that can act through paracrine mechanisms to exert multiple effects, such as the induction of wound healing (19), angiogenesis (22), the inhibition of scar formation following myocardial infarction (38) and multi-directional differentiation (39). Yoshihiko et al (40) demonstrated that adipose-derived stem/stromal cells can inhibit the formation of vocal cord scars through the regulation of the biological behavior of vocal fold fibroblasts and through the regulation of vocal folds inflammation. Yun et al (41) demonstrated that human ADSCs can stimulate scar remodeling in a pig wound model by decreasing the activity of mast cells, inhibiting the effects of TGF- $\beta$ on fibroblasts and decreasing the expression of MMP molecules. In vitro, human ADSCs were shown to inhibit TGF- $\beta 1$-induced differentiation of human dermal fibroblasts and keloid scar-derived fibroblasts in a paracrine manner (42).

The mode of action of ADSCs in the regulation of scar fibroblasts can occur either through direct contact, or through indirect non-contact mechanisms $(16,17)$. The present study established an indirect co-culture system of ADSCs and fibroblasts, including hypertrophic scar fibroblasts and keloid fibroblasts, using a Transwell chamber wherein ADSCs were not in direct contact with fibroblasts. However, in animal experiments, ADSCs are in direct contact with scar fibroblasts. While a study has indicated that local injection of adipose stem cells can promote healing and reduce the risk of scar formation during healing of the injury site (43), ADSCs-conditioned medium was alone able to alter the biological behavior of target cells $(44,45)$. Therefore, the interaction between the two cell types could be achieved through the influence of receptors, in addition to their direct interaction.

The present study observed that co-culture with ADSCs inhibited the protein expression of TGF- $\beta 1$, p-Smad2/Smad2, p-Smad3/Smad3 and Smad7 in HSFs and KFs. The TGF- $\beta$ family is highly conserved and its members are widely expressed during embryonic and tissue development, where they have been shown to exhibit different biological functions in a cell-dependent and condition-dependent manner (46). TGF- $\beta 1$ is a representative cytokine of the TGF- $\beta$ family that plays an important role in the regulation of the biological behavior of different cell types at different stages of development (46). TGF- $\beta 1$ exists in complex regulatory networks with different cell signaling pathway molecules that can regulate the expression of each other (46). In the process of wound healing, moderate secretion of TGF- $\beta 1$ can promote the proliferation and migration of fibroblasts, and can also accelerate the healing of wounds $(47,48)$. Jung et al (49) demonstrated that ADSCs can downregulate the expression of type-1 collagen and hyaluronic acid at the mRNA level via paracrine TGF- $\beta 1$ activity. Overexpression of TGF- $\beta 1$ has been reported to promote the secretion of extracellular matrix, which leads to scars formation $(50,51)$.

In summary, the present study demonstrated that ADSCs can affect the biological behavior of HSFs and KFs in vitro, specifically proliferation, migration and extracellular matrix synthesis, by regulating the TGF- $\beta 1 /$ Smad pathway.

\section{Acknowledgements}

Not applicable.

\section{Funding}

No funding was received.

\section{Availability of data and materials}

The datasets used and/or analyzed during the current study are available from the corresponding author on reasonable request.

\section{Authors' contributions}

LT conceived and designed the current study and contributed to writing the manuscript. FX and JX performed the experiments. JL, CZ, LY, XM and MZ analyzed and interpreted the data. All authors read and approved the final manuscript.

\section{Ethics approval and consent to participate}

All participants in the present study signed informed consents, and the study was approved by the Ethics Committee of Plastic 
Surgery Hospital, Chinese Academy of Medical Sciences and Peking Union Medical College (Beijing, China).

\section{Patient consent for publication}

All the participants in the present study signed informed consents.

\section{Competing interests}

The authors declare that they have no competing interests.

\section{References}

1. Fearmonti RM, Bond JE, Erdmann D, Levin LS, Pizzo SV and Levinson H: The modified patient and observer scar assessment scale: A novel approach to defining pathologic and nonpathologic scarring. Plast Reconstr Surg 129: 242-247, 2012.

2. Bock O, Schmid-Ott G, Malewski P and Mrowietz U: Quality of life of patients with keloid and hypertrophic scarring. Arch Dermatol Res 297: 433-438, 2006.

3. Rohrer TE and Gold M: Introduction to special issue on hypertrophic scars and keloids. Dermatol Surg 43 (Suppl 1): S1-S2, 2017.

4. Seifert $\mathrm{O}$ and Mrowietz U: Keloid scarring: Bench and bedside. Arch Dermatol Res 301: 259-272, 2009.

5. Gauglitz GG, Korting HC, Pavicic T, Ruzicka T and Jeschke MG: Hypertrophic Scarring and Keloids: Pathomechanisms and current and emerging treatment strategies. Mol Med 17: 113-125, 2011.

6. Nakajima H, Uchida K, Guerrero AR, Watanabe S, Sugita D, Takeura N, Yoshida A, Long G, Wright KT and Johnson WE: Transplantation of mesenchymal stem cells promotes an alternative pathway of macrophage activation and functional recovery after spinal cord injury. J Neurotrauma 29: 1614-1625, 2012.

7. Schurgers E, Kelchtermans H, Mitera T, Geboes L and Matthys P: Discrepancy between the in vitro and in vivo effects of murine mesenchymal stem cells on T-cell proliferation and collagen-induced arthritis. Arthritis Res Ther 12: R31, 2010.

8. Kim WS, Park BS, Kim HK, Park JS, Kim KJ, Choi JS, Chung SJ, Kim DD and Sung JH: Evidence supporting antioxidant action of adipose-derived stem cells: Protection of human dermal fibroblasts from oxidative stress. J Dermatol Sci 49: 133-142, 2008.

9. Hiwatashi N, Bing R, Kraja I and Branski RC: Mesenchymal stem cells have antifibrotic effects on transforming growth factor- $\beta 1$-stimulated vocal fold fibroblasts. Laryngoscope 127: E35-E41, 2017.

10. Smith AN, Willis E, Chan VT, Muffley LA, Isik FF, Gibran NS and Hocking AM: Mesenchymal stem cells induce dermal fibroblast responses to injury. Exp Cell Res 316: 48-54, 2010.

11. Harvestine JN, Orbay H, Chen JY, Sahar DE and Leach JK: Cell-secreted extracellular matrix, independent of cell source, promotes the osteogenic differentiation of human stromal vascular fraction. J Mater Chem B 6: 4104-4115, 2018.

12. Antoniou KM, Papadaki HA, Soufla G, Kastrinaki MC, Damianaki A, Koutala H, Spandidos DA and Siafakas NM: Investigation of bone marrow mesenchymal stem cells (BM MSCs) involvement in idiopathic pulmonary fibrosis (IPF). Respir Med 104: 1535-1542, 2010.

13. Yang D, Sun S, Wang Z, Zhu P, Yang Z and Zhang B: Stromal cell-derived factor-1 receptor CXCR4-overexpressing bone marrow mesenchymal stem cells accelerate wound healing by migrating into skin injury areas. Cell Reprogram 15: 206-215, 2013.

14. Yuben M, Daniel A, Ursula M, Samuel CS, Jorge T, Sivakami I, Richard B and Alan T: Human umbilical cord mesenchymal stem cells reduce fibrosis of bleomycin-induced lung injury. Am J Pathol 175: 303-313, 2009.

15. Lee MJ, Jung J, Na KH, Moon JS, Lee HJ, Kim JH, Kim GI, Kwon SW, Hwang SG and Kim GJ: Anti-fibrotic effect of chorionic plate-derived mesenchymal stem cells isolated from human placenta in a rat model of $\mathrm{CCl}(4)$-injured liver: Potential application to the treatment of hepatic diseases. J Cell Biochem 111: 1453-1463, 2010.
16. Bunnell BA: Adipose-derived stem cells. Methods Mol Biol 5: 59-67, 2008.

17. Ma T, Sun J, Zhao Z, Lei W, Chen Y, Wang X, Yang J and Shen Z: A brief review: Adipose-derived stem cells and their therapeutic potential in cardiovascular diseases. Stem Cell Res Ther 8: 124, 2017.

18. Yang D, Wang W, Li L, Peng Y, Chen P, Huang H, Guo Y, Xia X, Wang $\mathrm{Y}$ and Wang $\mathrm{H}$ : The relative contribution of paracine effect versus direct differentiation on adipose-derived stem cell transplantation mediated cardiac repair. PLoS One 8: e59020, 2013.

19. Kim WS, Park BS, Sung JH, Yang JM, Park SB, Kwak SJ and Park JS: Wound healing effect of adipose-derived stem cells: A critical role of secretory factors on human dermal fibroblasts. J Dermatol Sci 48: 15-24, 2007.

20. Lee SH, Lee JH and Cho KH: Effects of human adipose-derived stem cells on cutaneous wound healing in nude mice. Ann Dermatol 23: 150-155, 2011.

21. Maharlooei MK, Bagheri M, Solhjou Z, Jahromi BM, Akrami M, Rohani L, Monabati A, Noorafshan A and Omrani GR: Adipose tissue derived mesenchymal stem cell (AD-MSC) promotes skin wound healing in diabetic rats. Diabetes Res Clin Pract 93: 228-234, 2011.

22. Gao W, Qiao X, Ma S and Cui L: Adipose-derived stem cells accelerate neovascularization in ischaemic diabetic skin flap via expression of hypoxia-inducible factor-1 $\alpha$. J Cell Mol Med 15: 2575-2585, 2011.

23. Bock O, Yu H, Zitron S, Bayat A, Ferguson MWJ and Mrowietz U: Studies of transforming growth factors beta 1-3 and their receptors I and II in fibroblast of keloids and hypertrophic scars. Acta Derm Venereol 85: 216-220, 2005.

24. Wong VW, You F, Januszyk M, Gurtner GC and Kuang AA: Transcriptional profiling of rapamycin-treated fibroblasts from hypertrophic and keloid scars. Ann Plast Surg 72: 711-719, 2014.

25. Tao J, Zhang J, Ling Y, Mccall CE and Liu TF: Mitochondrial sirtuin 4 resolves immune tolerance in monocytes by rebalancing glycolysis and glucose oxidation homeostasis. Front Immunol 9: 419, 2018

26. O'Leary R, Wood EJ and Guillou PJ: Pathological scarring: Strategic interventions. Eur J Surg 168: 523-534, 2002.

27. Sarrazy V, Billet F, Micallef L, Coulomb B and Desmoulière A: Mechanisms of pathological scarring: Role of myofibroblasts and current developments. Wound Repair Regen 19 (Suppl 1): S10-S15, 2011.

28. Wagner JA: Therapy of pathological scars. J Dtsch Dermatol Ges 11: 1139-1157, 2013.

29. Liu YL, Liu WH, Sun J, Hou TJ, Liu YM, Liu HR, Luo YH, Zhao NN, Tang Y and Deng FM: Mesenchymal stem cell-mediated suppression of hypertrophic scarring is p53 dependent in a rabbit ear model. Stem Cell Res Ther 5: 136, 2014.

30. Zhang Q, Liu LN, Yong Q, Deng JC and Cao WG: Intralesional injection of adipose-derived stem cells reduces hypertrophic scarring in a rabbit ear model. Stem Cell Res Ther 6: 145, 2015.

31. Jia SS, Li WY, Liu X and Li LY: Transforming growth factor- $\beta 1$ induces differentiation of bone marrow-derived mesenchymal stem cells into myofibroblasts via production of reactive oxygen species. Beijing Da Xue Xue Bao Yi Xue Ban 47: 737-742, 2015 (In Chinese).

32. Lichtman MK, Otero-Vinas $M$ and Falanga V: Transforming grow th factors $\beta$ (TGF- $\beta$ ) isoforms in wound healing and fibrosis. Wound Repair Regen 24: 215-222, 2016.

33. Stagg J: Immune regulation by mesenchymal stem cells: Two sides to the coin. Tissue Antigens 69: 1-9, 2010.

34. Park JE, Seo YK, Yoon HH, Kim CW, Park JK and Jeon S: Electromagnetic fields induce neural differentiation of human bone marrow derived mesenchymal stem cells via ROS mediated EGFR activation. Neurochem Int 62: 418-424, 2013.

35. Manieri NA, Mack MR, Himmelrich MD, Worthley DL, Hanson EM, Lars E, Wang TC and Stappenbeck TS: Mucosally transplanted mesenchymal stem cells stimulate intestinal healing by promoting angiogenesis. J Clin Invest 125: 3606-3618, 2015.

36. Zuk P, Zhu M, Mizuno H, Huang J, Futrell J, Katz A, Benhaim P, Lorenz $\mathrm{H}$ and Hedrick M: Multilineage cells from human adipose tissue: Implications for cell-based therapies. Tissue Eng 7: 211-228, 2001.

37. Zuk PA, Zhu M, Ashjian P, De Ugarte DA, Huang JI, Mizuno H, Alfonso ZC, Fraser JK, Benhaim P and Hedrick MH: Human adipose tissue is a source of multipotent stem cells. Mol Biol Cell 13: 4279-4295, 2002. 
38. Bayesgenis A, Soler-Botija C, Farré J, Sepúlveda P, Raya A Roura S, Prat-Vidal C, Gálvez-Montón C, Montero JA and Büscher D: Human progenitor cells derived from cardiac adipose tissue ameliorate myocardial infarction in rodents. J Mol Cell Cardiol 49: 771-780, 2010.

39. Cao Y, Sun Z, Liao L, Meng Y, Han Q and Zhao RC: Human adipose tissue-derived stem cells differentiate into endothelial cells in vitro and improve postnatal neovascularization in vivo. Biochem Biophys Res Commun 332: 370-379, 2005.

40. Yoshihiko K, Kobler JB, Herrera VLM and Zeitels SM: Perspectives on adipose-derived stem/stromal cells as potential treatment for scarred vocal folds: Opportunity and challenges. Curr Stem Cell Res Ther 5: 175-181, 2010.

41. Yun IS, Jeon YR, Lee WJ, Lee JW, Rah DK, Tark KC and Lew DH: Effect of human adipose derived stem cells on scar formation and remodeling in a pig model: A pilot study. Dermatol Surg 38: 1678-1688, 2012.

42. Spiekman M, Przybyt E, Plantinga JA, Gibbs S, van der Lei B and Harmsen MC: Adipose tissue-derived stromal cells inhibit TGF- $\beta 1$-induced differentiation of human dermal fibroblasts and keloid scar-derived fibroblasts in a paracrine fashion. Plast Reconstr Surg 134: 699-712, 2014.

43. Zonari A, Martins TM, Paula AC, Boeloni JN, Novikoff S, Marques AP, Correlo VM, Reis RL and Goes AM: Polyhydroxybutyrate-co-hydroxyvalerate structures loaded with adipose stem cells promote skin healing with reduced scarring. Acta Biomater 17: 170-181, 2015.

44. Zhang Y, Dong W, Wang J, Cai J and Wang Z: Human omental adipose-derived mesenchymal stem cell-conditioned medium alters the proteomic profile of epithelial ovarian cancer cell lines in vitro. Onco Targets Ther 10: 1655-1663, 2017.

45. Ivanova-Todorova E, Bochev I, Dimitrov R, Belemezova K, Mourdjeva M, Kyurkchiev S, Kinov P, Altankova I and Kyurkchiev D: Conditioned medium from adipose tissue-derived mesenchymal stem cells induces $\mathrm{CD}^{+}{ }^{+} \mathrm{FOXP} 3^{+}$cells and increases IL-10 secretion. J Biomed Biotechnol 2012: 295167, 2012.
46. Pardali E, Sanchez-Duffhues G, Gomez-Puerto MC and Dijke PT: TGF- $\beta$-induced endothelial-mesenchymal transition in fibrotic diseases. Int J Mol Sci 18: 2157, 2017.

47. Yichiang H, Chen MJ, Yu YM, Shunyao K and Chang CC: Suppression of TGF- $\beta 1 /$ SMAD pathway and extracellular matrix production in primary keloid fibroblasts by curcuminoids: Its potential therapeutic use in the chemoprevention of keloid. Arch Dermatol Res 302: 717-724, 2010.

48. Emami A, Halim AS, Salahshifar I, Yussof SJ, Khoo TL and Kannan TP: Association of TGF $\beta 1$ and SMAD4 variants in the etiology of keloid scar in the Malay population. Arch Dermatol Res 304: 541-547, 2012.

49. Jung H, Kim HH, Lee DH, Hwang YS, Yang HC and Park JC: Transforming growth factor-beta 1 in adipose derived stem cells conditioned medium is a dominant paracrine mediator determines hyaluronic acid and collagen expression profile. Cytotechnology 63: 57-66, 2011.

50. Shah M, Foreman DM and Ferguson MW: Neutralisation of TGF-beta 1 and TGF-beta 2 or exogenous addition of TGF-beta 3 to cutaneous rat wounds reduces scarring. J Cell Sci 108: 985-1002, 1995

51. Pohlers D, Brenmoehl J, Löffler I, Müller CK, Leipner C, Schultze-Mosgau S, Stallmach A, Kinne RW and Wolf G: TGF- $\beta$ and fibrosis in different organs-molecular pathway imprints. Biochim Biophys Acta 1792: 746-756, 2009.

(i) (3) $($ This work is licensed under a Creative Commons EY NC NO Attribution-NonCommercial-NoDerivatives 4.0 International (CC BY-NC-ND 4.0) License. 